\title{
SISTEMA PARA INFILTRAÇÃO DAS ÁGUAS PLUVIAIS NO SOLO E SUBSOLO DA BACIA DE CURITIBA EM VIAS URBANIZADAS
}

\author{
A SYSTEM TO PERMEATE THE PLUVIAL WATER IN SOIL AND SUBSOIL \\ OF CURITIBA BASIN AT URBAN STREETS
}

\author{
Vinicios Hyczy do Nascimento ${ }^{1}$, Ernani Francisco da Rosa Filho ${ }^{2}$, \\ Eduardo Chemas Hindi ${ }^{2}$ e Luiz Eduardo Mantovani ${ }^{2}$
}

\begin{abstract}
RESUMO O avanço do crescimento das cidades, por mais ordenado que seja, cria alterações no meio ambiente. Onde antes eram matas e campos, agora são casas, edifícios, ruas asfaltadas, galerias de águas pluviais, etc. O processo de impermeabilização do terreno é um dos fatores que alteram significativamente o ciclo hidrológico, pois impede a infiltração das águas no solo e subsolo e incrementa o seu escoamento superficial com o agravante aumento das velocidades de fluxo, causando enchentes, erosões e assoreamentos a jusante. As águas subterrâneas sofrem sensíveis alterações, pois não são recarregadas e, portanto, não alimentam os rios nas épocas de estiagem, havendo um decréscimo significativo da sua vazão de base. Neste contexto, vê-se a importância do estudo geológico da região em apreço, em especial a Formação Guabirotuba, a fim de implantar um sistema para infiltração das águas pluviais. O objetivo do trabalho, portanto, é idealizar um sistema de controle do escoamento das águas pluviais em vias públicas em pequena escala, através da instalação de caixas de captação de águas pluviais dotadas de sistema de contenção e infiltração destas águas na camada não saturada do solo e subsolo da Bacia Sedimentar de Curitiba, de modo a atenuar as alterações provocadas pela impermeabilização do solo. O sistema permitirá o abrandamento destas alterações ao meio ambiente, realimentando o lençol freático pontualmente e perenizando os rios nas épocas de estiagens, o que mitigará as conseqüências das enchentes, das erosões e do assoreamento em épocas de chuvas intensas.
\end{abstract}

Palavras-chave: impermeabilizção, infiltração, Formação Guabirotuba

\begin{abstract}
The development of the cities, no matter how orderly it is, changes the environment. Where there used to be fields and forests, there are now buildings, paved streets, galleries of pluvial waters, etc. The covering of land with impermeable surfaces is one of the factors that changes the hidrological cycle, because it obstructs the water percolation to the underground and increases the runoff, which causes floods, erosions and sedimentations. The underground water flow is substantially altered because it is not recharged, therefore, it does not feed the rivers at dry seasons anymore causing a decrease of the river flow. In this context, we see the importance of the geological study of Curitiba region, in order to implement a system which can infiltrate the pluvial waters. The objective of this study so, is to create a system of pluvial water flow control on public streets in a small scale, through the installation of "gully pots" made up with a contention and infiltration system of these waters at two points with different litologic features, the Guabirotuba's Formation and the Atuba Complex, in the insaturated layer of the soil and subsoil of Curitiba's sedimentary basin. The system will allow for the softening of these environmental changes, refeeding the underground water, keeping the river level in dry seasons and will mitigate the consequences of the floods, erosions and sedimentations in intensive rain seasons.
\end{abstract}

Keywords:

\section{INTRODUÇÃO}

O balanço hídrico em bacias urbanas alterase, com o aumento do volume do escoamento superficial e a redução da recarga natural dos aquíferos e da evapotranspiração. A tendência da redução da recarga dos aqüíferos produz o rebaixamento do nível freático e a diminuição das vazões fluviais durante as estiagens. Como existem ligações clandestinas na rede pluvial, a redução do fluxo natural é compensada pelo escoamento do esgoto, o que cria um ambiente de baixa qualidade de água, encontrado na maioria das cidades brasileiras. Em um eficiente sistema de rede de distribuição de água (sem vazamentos), rede de esgoto e tratamento, sem ligações clandestinas, o sistema urbano teria seus riachos praticamente secos durante as estiagens. Esse processo pode ser revertido com a utilização maior de superfícies permeáveis e áreas de infiltração.

De acordo com Giusti (1989), o Plano Diretor de Curitiba de 1966 desconsiderou completamente o suporte geológico. Foi criado um desequilíbrio sensível nos processos ecológicos do Município, principalmente quanto à proteção do solo e preservação dos mananciais e zonas de recargas dos aqǘferos. Surgiram zonas com excessiva impermeabilização devido às edificações que são prejudiciais a aeração, insolação e infiltração das águas pluviais no solo.

\footnotetext{
${ }^{1}$ Mestrando do Curso de Geologia Ambiental da UFPR (vinicioshn@ufpr.br)

${ }^{2}$ UFPR-DEGEOL-LPH - Laboratório de Pesquisas Hidrogeológicas (ernani@ufpr.br), (hindi@ufpr.br), (lem@ufpr.br
} 


\section{CONSIDERAÇÕES SOBRE A GEOLOGIA}

A Geologia do Município de Curitiba compreende duas situações fundamentais. A primeira, representada pelos terrenos précambrianos, é constituída pelas rochas do Complexo Cristalino e do Grupo Açungui e, a segunda, é constituída pelas formações cenozóicas do Neogeno, possivelmente datando das séries do Mioceno (23 Ma até 7,2 Ma), pela Formação Guabirotuba e durante as séries do Pleistoceno (1,8 Ma até o presente) pelos depósitos aluvionares. (SALAMUNI; EBERT; HASUI, 2004; RIFFEL, 2005).

Segundo Giusti (1989), os depósitos de sedimentos da Formação Guabirotuba, atingem espessuras máximas de até $80 \mathrm{~m}$, na porção central da Bacia de Curitiba. Esses depósitos compreendem sequiências litológicas nas quais predominam os argilitos e areias arcosianas, sendo que em quantidades reduzidas ocorrem sedimentos rudáceos.

A Formação Guabirotuba é caracterizada por rochas sedimentares depositadas durante o preenchimento da Bacia de Curitiba. São argilas de composições bentoníticas a montmoriloníticas, entremeadas por lentes de composição arcosiana a quartzosas, com espessuras variáveis. Os aquíferos da Formação Guabirotuba são exclusivamente ligados às lentes arcosianas ou quartzosas e sua potencialidade para águas subterrâneas é função direta dos menores teores de argilas e das maiores espessuras dessas lentes.

Bigarella e Salamuni (1962) designaram formalmente os sedimentos do Quartenário antigo (1,8 Ma à 10.000 anos atrás) de Formação Guabirotuba, a qual ocorre numa área de cerca de $3.000 \mathrm{~km}^{2}$. Os materiais constituintes destes sedimentos foram determinados como argilitos, seguindo-se os arcósios e depósitos rudáceos, além de pequenos horizontes de caliche, anteriormente interpretados como margas. Todas estas litologias foram descritas como materiais inconsolidados ou "quando muito, endurecidos por soluções de carbonato de cálcio". Para Bigarella e Salamuni (1962), a sedimentação é típica de leques aluviais e depósitos fluviais, ou, ainda, possivelmente de playa, cujas espessuras não ultrapassam os $60 \mathrm{~m}$, apresentando coloração original cinza esverdeada.

Bigarella e Salamuni (1962) consideram ainda que, os depósitos recentes aluvionares, foram sedimentados por rios meandrantes e por extensas inundações nas várzeas. Estes depósitos apresentam características granulométricas variadas, porém os horizontes que podem ser considerados rudáceos são poucos, sendo rara a presença de seixos.

Lopes (1966) salientou as vastas planícies aluvionares, principalmente ao longo das drenagens secundárias, afluentes do rio Iguaçu, tais como os rios, Verde, Passaúna, Barigui e Belém. Este autor descreveu estes sedimentos como essencialmente arenosos, havendo camadas de argilas, com elevado teor orgânico e apresentando em geral estratificação plana e, de forma localizada, estratificações cruzadas.

\section{OBJETIVOS}

Idealizar um sistema de controle do escoamento das águas pluviais em vias públicas, através da instalação de caixas de captação de águas pluviais dotadas de sistema de contenção e infiltração destas águas na camada não saturada do solo e subsolo da Bacia Sedimentar de Curitiba, de modo a atenuar as alterações provocadas pela impermeabilização do solo. $\mathrm{O}$ sistema permitirá o abrandamento destas alterações ao meio ambiente, realimentando o lençol freático pontualmente e perenizando os rios nas épocas de estiagens, o que mitigará as conseqüências das enchentes, das erosões e do assoreamento em épocas de chuvas intensas.

\section{LOCALIZAÇÃO}

O local "campo de provas" onde foi realizado o ensaio para verificação da capacidade de infiltração das águas pluviais através dos solos está localizado no campus III da Universidade Federal do Paraná (Figura 1).

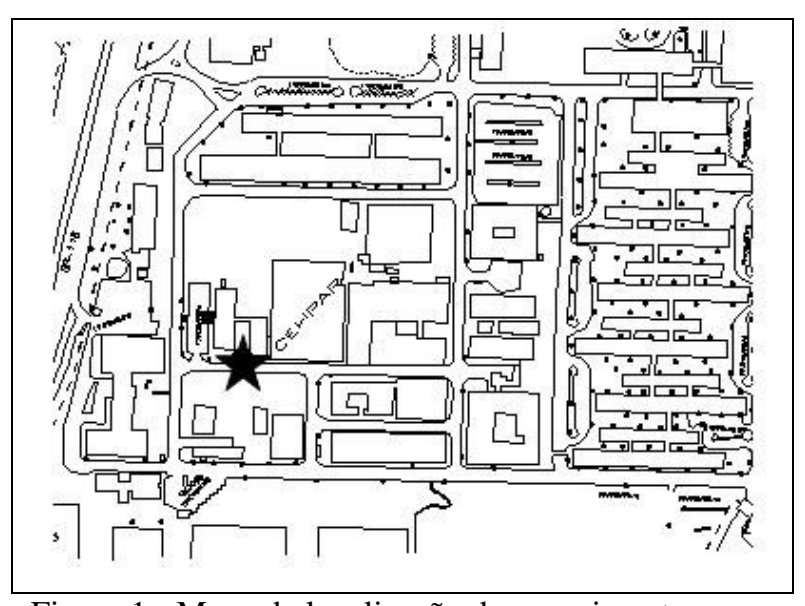

Figura 1 - Mapa de localização do experimento Fonte: Prefeitura da Cidade Universitária 
Tabela 1: Índice diário de chuvas >20mm no mês de janeiro (1999-2006) na cidade de Curitiba-PR.

\begin{tabular}{|c|c|c|c|c|c|}
\hline Data & $\begin{array}{l}\text { Horário da } \\
\text { ocorrência }\end{array}$ & $\begin{array}{l}\text { Precipi-tação } \\
(\mathrm{mm})\end{array}$ & $\begin{array}{c}\text { Total da } \\
\text { precipitação diária } \\
(\mathrm{mm})\end{array}$ & $\begin{array}{c}\text { SRI }(*)(\mathrm{mm}) \\
\text { (reserv. e infiltração) }\end{array}$ & $\begin{array}{c}\text { Segue pela } \\
\text { Galeria pluvial } \\
(\mathrm{mm})\end{array}$ \\
\hline \multicolumn{6}{|l|}{1999} \\
\hline 01/jan & $16: 00$ & 27,4 & 27,4 & 20,0 & 7,4 \\
\hline 16/jan & $19: 00$ & 29,8 & & & \\
\hline 16/jan & $20: 00$ & 23,6 & & & \\
\hline 16/jan & 21:00 & 7,4 & 60,8 & 20,0 & 40,8 \\
\hline 26/jan & $17: 00$ & 6,8 & & & \\
\hline 26/jan & $18: 00$ & 29,8 & 36,6 & 20,0 & 16,6 \\
\hline \multicolumn{6}{|l|}{2000} \\
\hline 18/jan & $17: 00$ & 6,4 & & & \\
\hline 18/jan & $18: 00$ & 24,8 & 31,2 & 20,0 & 11,2 \\
\hline 31/jan & 09:00 & 9,6 & & & \\
\hline 31/jan & $12: 00$ & 5,4 & & & \\
\hline 31/jan & $14: 00$ & 11,0 & & & \\
\hline 31/jan & $15: 00$ & 30,2 & & & \\
\hline 31/jan & $16: 00$ & 7,8 & 64,0 & 20,0 & 44,0 \\
\hline \multicolumn{6}{|l|}{2001} \\
\hline 23/jan & $18: 00$ & 35,2 & & & \\
\hline 23/jan & 19:00 & 16,4 & 51,6 & 20,0 & 31,6 \\
\hline \multicolumn{6}{|l|}{2002} \\
\hline 12/jan & $15: 00$ & 8,8 & & & \\
\hline 12/jan & 17:00 & 6,4 & & & \\
\hline 12/jan & $18: 00$ & 15,0 & & & \\
\hline 12/jan & 19:00 & 11,0 & 41,2 & 20,0 & 21,2 \\
\hline 30/jan & $17: 00$ & 44,2 & 44,2 & 20,0 & 24,2 \\
\hline \multicolumn{6}{|l|}{2004} \\
\hline 24/jan & $15: 00$ & 7,0 & & & \\
\hline 24/jan & $16: 00$ & 10,6 & & & \\
\hline 24/jan & 18:00 & 5,4 & 23 & 20,0 & 3,0 \\
\hline 29/jan & $20: 00$ & 24,2 & 24,2 & 20,0 & 4,2 \\
\hline \multicolumn{6}{|l|}{2005} \\
\hline 10/jan & $18: 00$ & 27,8 & 27,8 & 20,0 & 7,8 \\
\hline \multicolumn{6}{|l|}{2006} \\
\hline 19/jan & $16: 00$ & 5,0 & & & \\
\hline 19/jan & $22: 00$ & 16,4 & 21,4 & 20.0 & 1,4 \\
\hline
\end{tabular}

\section{DADOS CLIMÁTICOS}

De acordo com os dados pluviométricos obtidos junto ao SIMEPAR, referentes ao mês de janeiro (historicamente o mais chuvoso do ano em Curitiba), entre 1999 e 2006 foram registrados 12 eventos com pluviosidade acima de $20 \mathrm{~mm} /$ dia. Desses 12 eventos que ocorreram nos últimos sete anos, 5 deles podem ser considerados críticos por conta de um índice acima de $40 \mathrm{~mm} / \mathrm{dia}$, sendo que outros 7 eventos apresentam índices entre 20 e $40 \mathrm{~mm} /$ dia (tabela1). Após a implantação do sistema de reservação e infiltração (SRI) das águas pluviais, apenas 2 eventos continuariam sendo críticos (acima de 40 $\mathrm{mm} /$ dia) e 3 eventos com possibilidades de ocorrência de alagamentos (entre 20 e 40 $\mathrm{mm} / \mathrm{dia}$ ). Os demais eventos apresentam valores menores do que $20 \mathrm{~mm} / \mathrm{dia}$, considerados neste trabalho como pouco significativos a ponto de causar enchentes na cidade.

\section{MATERIAIS E MÉTODOS}

\section{Trabalhos de campo}

Os primeiros trabalhos de campo foram realizados para a determinação da capacidade de absorção da água pelo solo na região de Curitiba. Para tal, foi utilizado o método do ensaio de infiltração citado na NBR 7229/1993 - Projeto, construção e operação de sistemas de tanques sépticos. Foram executadas três "covas 
cilíndricas" com diâmetro de $0,15 \mathrm{~m}$, com espaçamento de aproximadamente $5 \mathrm{~m}$ entre si, sendo extraídas de cada uma delas materiais em profundidades de 0,5 m, 1,0 m e 1,5 m (Figura 2).

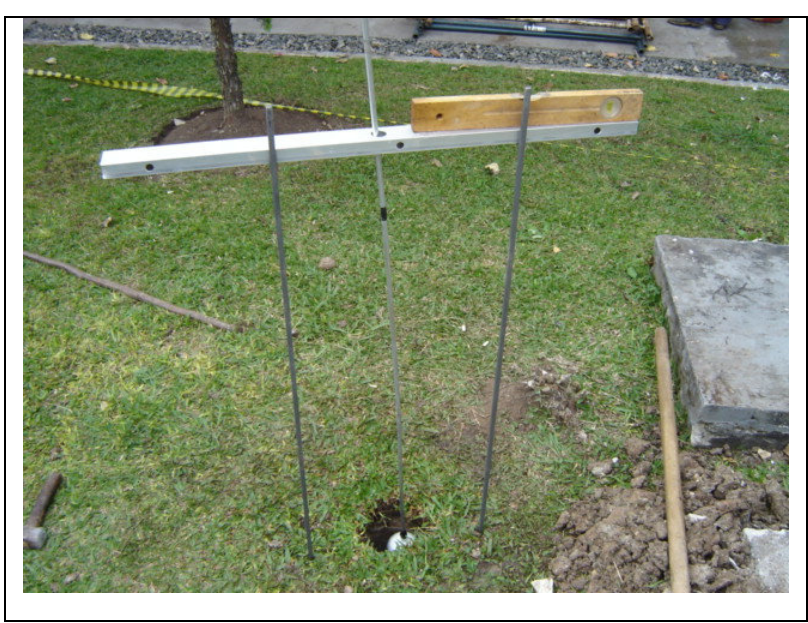

Figura 2: Aspecto das covas cilíndricas utilizadas no experimento. Realizada em 05/2006.

Cada uma das covas cilíndricas foi preenchida com água, tendo sido mantidas com igual nível durante 4 horas. Na Cova cilíndrica número 1, o nível da água baixava muito lentamente, enquanto nas covas cilíndricas de números 2 e 3 , os níveis da água rebaixaram logo após o enchimento, sendo que a sua estabilização, de forma lenta, ocorreu nos últimos instantes das 4 horas de observações.

$\mathrm{Na}$ sequiência dos ensaios, as covas cilíndricas foram novamente preenchidas com água para uma observação com duração de 24 horas, sem que houvesse a ocorrência de chuvas. O nível da água na cova cilíndrica 1 teve, após este tempo, um pequeno rebaixo, indicando portanto, tratar-se de um solo de muito baixa permeabilidade. Com relação às covas cilíndricas 2 e 3, observou-se visualmente que houve um rebaixamento mais acentuado da água em seu interior.

$\mathrm{Na}$ sequiência, as covas cilíndricas 1,2 e 3 foram novamente preenchidas com $76 \mathrm{~cm}$ de altura de água, medindo-se um tempo de $22 \mathrm{~min}$, 5 min e $1 \mathrm{~s}$ e 2 min e $7 \mathrm{~s}$ para que ocorresse um rebaixamento de $5,1 \mathrm{~cm}$, respectivamente..

Tendo em conta os tempos determinados e aplicando-os ao gráfico do método citado na NBR 7229, obtiveram-se os seguintes coeficientes de permeabilidade $(\mathrm{K})$ :

Cova cilíndrica $1=21 \mathrm{~L} / \mathrm{m}^{2}$.dia ou $2,43 \times 10^{-5} \mathrm{~cm} / \mathrm{s}$; Cova cilíndrica $2=64 \mathrm{~L} / \mathrm{m}^{2}$.dia ou 7,41 x $10^{-5} \mathrm{~cm} / \mathrm{s}$; Cova cilíndrica $3=89 \mathrm{~L} / \mathrm{m}^{2}$.dia ou $1,03 \times 10^{-4} \mathrm{~cm} / \mathrm{s}$.
Como a referida norma exige a adoção do menor valor para o coeficiente de permeabilidade $(\mathrm{K})$, adotou-se o seguinte valor: $21 \mathrm{~L} / \mathrm{m}^{2}$.dia ou $2,43 \times 10^{-5} \mathrm{~cm} / \mathrm{s}$.

\section{Trabalhos de laboratório}

Os trabalhos de laboratório se restringiram a análises granulométricas por peneiramento e sedimentação (NBR-7181/84), as quais foram realizadas no LAME (Laboratório de Materiais e Estruturas) da UFPR. Os resultados são apresentados a seguir.

$\begin{array}{lll}\begin{array}{l}\text { Cova } \\ \text { cilíndrica } 1\end{array} & \begin{array}{l}0,5 \mathrm{~m} \text { de } \\ \text { profundidade }\end{array} & \text { Argila Arenosa } \\ & \begin{array}{l}1,0 \mathrm{~m} \text { de } \\ \text { profundidade } \\ 1,5 \mathrm{~m} \text { de } \\ \text { profundidade }\end{array} & \text { Argila Siltosa } \\ & \text { Argila Arenosa } \\ \begin{array}{l}\text { Cova } \\ \text { cilíndrica 2 }\end{array} & \begin{array}{l}0,5 \mathrm{~m} \text { de } \\ \text { profundidade }\end{array} & \text { Argila Arenosa } \\ & \begin{array}{l}1,0 \mathrm{~m} \text { de } \\ \text { profundidade }\end{array} & \text { Argila Arenosa } \\ & \begin{array}{l}1,5 \mathrm{~m} \text { de } \\ \text { profundidade }\end{array} & \text { Argila Arenosa } \\ & \begin{array}{l}0,5 \mathrm{~m} \text { de } \\ \text { profundidade }\end{array} & \text { Argila Arenosa } \\ \text { Cova } \\ \text { cilíndrica 3 } & \begin{array}{l}1,0 \mathrm{~m} \text { de } \\ \text { profundidade }\end{array} & \text { Argila Arenosa } \\ & \begin{array}{l}1,5 \mathrm{~m} \text { de } \\ \text { profundidade }\end{array} & \text { Silte Argiloso } \\ & & \end{array}$

Esses resultados tornam evidente que a capacidade de infiltração é maior na cova cilíndrica 3 em relação à cova cilíndrica 2 , sendo que nesta, a capacidade de infiltração é maior do que na cova cilíndrica 1.

Para efeito de comparação com os resultados obtidos neste "campo de prova", foram feitas coletas de mais dois tipos de solos, sendo nesses casos materiais de alteração das rochas pelíticas da Formação Guabirotuba.

Nesse experimento, foi implantado um sistema de reservação com infiltração das águas pluviais, aqui denominados de A e B.

\begin{tabular}{|c|c|c|}
\hline Solo A & $\begin{array}{l}3,0 \mathrm{~m} \\
\text { profundidade }\end{array}$ & Argila Siltosa \\
\hline Solo B & $\begin{array}{l}3,0 \mathrm{~m} \\
\text { profundidade }\end{array}$ & Areia Argilosa \\
\hline
\end{tabular}

O solo A é solo da Formação Guabirotuba e é proveniente do mesmo local das covas cilíndricas 1,2 e 3 , sendo que o solo $\mathrm{B}$ foi retirado do fundo do sistema implantado na rua Presidente Wilson, no bairro do Uberaba em Curitiba; neste caso, trata-se de material extraído 
de um aterro pois contém pedaços de tijolos. A composição do material analisado é apresentada nas tabelas 2 e 3 .

Tabela 2: Composição do solo A (material argiloso e siltoso)

\begin{tabular}{l|c|c|c}
\hline Material & $\begin{array}{c}\text { Diâmetro } \\
(\mathrm{mm})\end{array}$ & \% passa & $\%$ \\
\hline Argila & 0,002 & 38,2 & 38,2 \\
\hline Silte & 0,060 & 73,2 & 35,0 \\
\hline Areia & 2,000 & 82,1 & 8,9 \\
\hline Pedregulho & 4,800 & 99,5 & 17,4 \\
\hline Pedra & 60,00 & 100,0 & 0,5
\end{tabular}

Tabela 3: Composição do solo B (material arenoargiloso).

\begin{tabular}{l|c|c|c}
\hline \multicolumn{1}{c|}{ Material } & $\begin{array}{c}\text { Diâmetro } \\
(\mathrm{mm})\end{array}$ & $\%$ passa & $\%$ \\
\hline Argila & 0,002 & 22,4 & 22,4 \\
\hline Silte & 0,060 & 42,5 & 20,1 \\
\hline Areia & 2,000 & 92,0 & 49,5 \\
\hline Pedregulho & 4,800 & 96,1 & 4,1 \\
\hline Pedra & 60,00 & 100,0 & 3,9
\end{tabular}

\section{DIMENSIONAMENTO DO SISTEMA DE RESERVAÇÃO E INFILTRAÇÃO}

Para o dimensionamento do sistema de reservação e infiltração (SRI) levou-se em consideração o fato de que ele vai compor um sistema de micro-drenagem e ele deve ser o menor possível para que se torne viável do ponto de vista econômico, e grande o suficiente para armazenar e infiltrar uma boa parcela de água. Após uma análise disto juntamente com os dados de chuvas da Tabela 1, chegou-se numa conclusão de que o SRI deveria ter uma capacidade de armazenamento para uma chuva de $20 \mathrm{~mm}$, pois este é um valor que pode ser considerado como limite para um possível alagamento. Portanto numa chuva de $40 \mathrm{~mm}$, a metade ficará retida no SRI e irá se infiltrar no solo e a outra metade escoará pela galeria de águas pluviais. A área de contribuição corresponde à área da rua que contribuirá para uma caixa de captação de águas pluviais.

A Prefeitura Municipal de Curitiba tem adotado uma caixa de captação para cada $30 \mathrm{~m}$, uma em cada lado da rua, considerando $7 \mathrm{~m}$ de largura; esta contribuição é de 30 x 3,5 =105 m².

Para a chuva de $20 \mathrm{~mm}$, o volume de contenção e infiltração será:

$$
\mathrm{V}=105 \times 0,02=2,1 \mathrm{~m}^{3} .
$$

A implantação desse experimento foi feita através da instalação de duas tubulações de concreto com 1,2 m de diâmetro, com o fundo preenchido com $30 \mathrm{~cm}$ de brita para evitar a erosão, possibilitando o armazenamento de 2,26 $\mathrm{m}^{3}$ (ver Figuras 3 e 4 ).

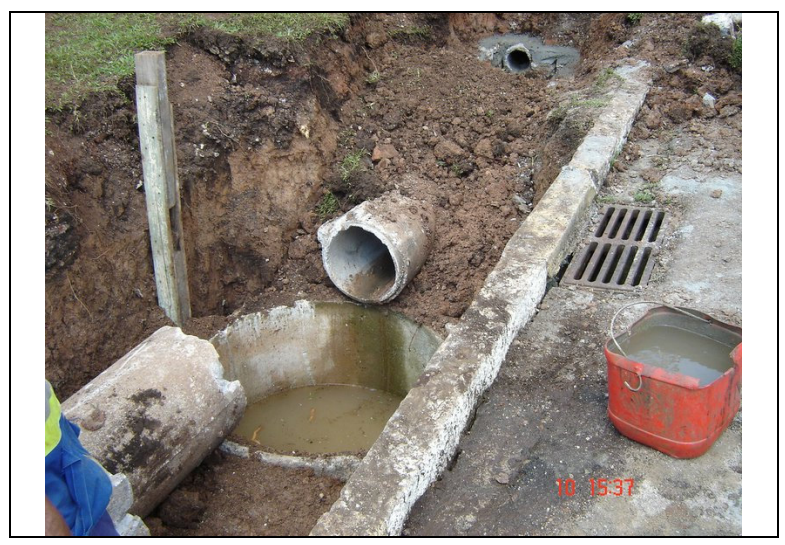

Figura 3: Protótipo implantado no Centro Politécnico. Realizada em 01/2007

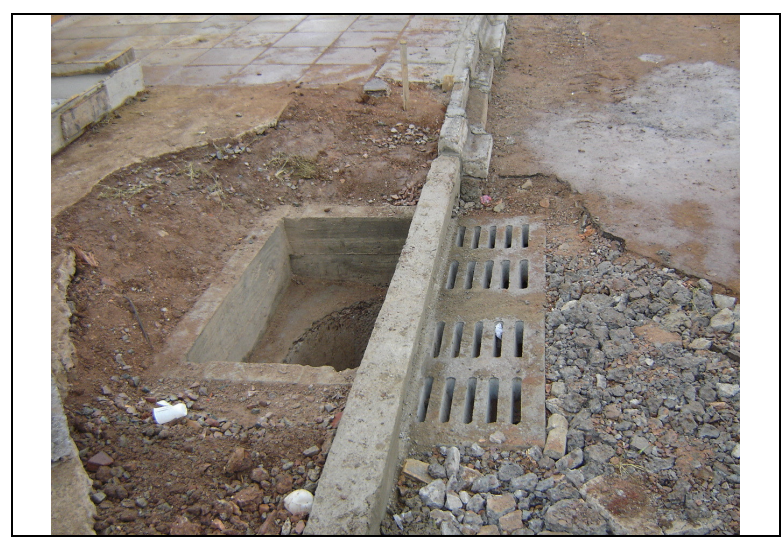

Figura 4: Protótipo implantado na rua Pres. Wilson. Realizada em 08/2006

\section{Resultados dos experimentos}

O protótipo implantado no Centro Politécnico da UFPR (Figura 3) secciona um solo mais argiloso e, por esta razão, apresenta uma capacidade menor de infiltração da água, enquanto o protótipo instalado à Rua Presidente Wilson, no bairro Uberaba (Figura 4), o solo apresenta característica mais arenoso e, portanto, com maior capacidade de infiltração da água. $\mathrm{O}$ comportamento dos rebaixamentos da água nos dois experimentos está demonstrado nas Tabelas 5 e 6 . Os reservatórios foram cheios com água no dia anterior ao início do monitoramento (entendese por N.A. máx, o nível máximo de reservação de água dentro do SRI a partir do qual, a água extravasa e escoa pela galeria de águas pluviais). $\mathrm{O}$ rebaixo do N.A. significa a ocorrência da infiltração da água no solo e a elevação do N.A., significa que ocorreram chuvas entre uma medição e a outra, por exemplo, houveram chuvas entre as medições do dia 15 e 16/3/2007, idem entre os dias 23 e 26/3/2007, entre os dias $30 / 3$ e 02/4/2007 e entre os dias 03 e 04/4/2007, (Tabelas 5 e 6 ). 
Tabela 5: Solo A: Argila Siltosa da Formação Guabirotuba. Realizado em março/abril/2007

\begin{tabular}{|c|c|c|}
\hline \multicolumn{1}{|c|}{ local: Centro Politécnico } \\
\hline Data & Hora & NívEL DA ÁGUA \\
\hline $13 / 3 / 2007$ & $16: 00$ & $30 \mathrm{~cm}$ abaixo do N.A. máx. \\
\hline $14 / 3 / 2007$ & $10: 30$ & $40 \mathrm{~cm}$ abaixo do N.A. máx. \\
\hline $15 / 3 / 2007$ & $14: 00$ & $44 \mathrm{~cm}$ abaixo do N.A. máx. \\
\hline $16 / 3 / 2007$ & $16: 30$ & $31 \mathrm{~cm}$ abaixo do N.A. máx. \\
\hline $17 / 3 / 2007$ & $11: 00$ & $41 \mathrm{~cm}$ abaixo do N.A. máx. \\
\hline $19 / 3 / 2007$ & $11: 30$ & $47 \mathrm{~cm}$ abaixo do N.A. máx. \\
\hline $20 / 3 / 2007$ & $10: 40$ & $55 \mathrm{~cm}$ abaixo do N.A. máx. \\
\hline $21 / 3 / 2007$ & $16: 30$ & $59 \mathrm{~cm}$ abaixo do N.A. máx. \\
\hline $22 / 3 / 2007$ & $10: 30$ & $59 \mathrm{~cm}$ abaixo do N.A. máx. \\
\hline $23 / 3 / 2007$ & $11: 15$ & $59 \mathrm{~cm}$ abaixo do N.A. máx. \\
\hline $26 / 3 / 2007$ & $14: 50$ & $38 \mathrm{~cm}$ abaixo do N.A. máx. \\
\hline $27 / 3 / 2007$ & $11: 30$ & $49 \mathrm{~cm}$ abaixo do N.A. máx. \\
\hline $28 / 3 / 2007$ & $16: 45$ & $52 \mathrm{~cm}$ abaixo do N.A. máx. \\
\hline $29 / 3 / 2007$ & $15: 45$ & $54 \mathrm{~cm}$ abaixo do N.A. máx. \\
\hline $30 / 3 / 2007$ & $10: 40$ & $56 \mathrm{~cm}$ abaixo do N.A. máx. \\
\hline $02 / 4 / 2007$ & $15: 15$ & $51 \mathrm{~cm}$ abaixo do N.A. máx. \\
\hline $03 / 4 / 2007$ & $11: 30$ & $56 \mathrm{~cm}$ abaixo do N.A. máx. \\
\hline $04 / 4 / 2007$ & $14: 45$ & $41 \mathrm{~cm}$ abaixo do N.A. máx. \\
\hline $05 / 4 / 2007$ & $08: 45$ & $48 \mathrm{~cm}$ abaixo do N.A. máx. \\
\hline $09 / 4 / 2007$ & $08: 50$ & $62 \mathrm{~cm}$ abaixo do N.A. máx. \\
\hline $10 / 4 / 2007$ & $10: 45$ & $60 \mathrm{~cm}$ abaixo do N.A. máx. \\
\hline $11 / 4 / 2007$ & $09: 00$ & $61 \mathrm{~cm}$ abaixo do N.A. máx. \\
\hline $12 / 4 / 2007$ & $09: 10$ & $61 \mathrm{~cm}$ abaixo do N.A. máx. \\
\hline $13 / 4 / 2007$ & $10: 00$ & $64 \mathrm{~cm}$ abaixo do N.A. máx. \\
\hline
\end{tabular}

Tabela 6: Solo B: Areia Siltosa. Realizado em março/abril/2007

\begin{tabular}{|c|c|c|}
\hline \multicolumn{3}{|c|}{ local: rua Pres. Wilson } \\
\hline $15 / 3 / 2007$ & Hora & NíVEL DA ÁGUA \\
\hline $16 / 3 / 2007$ & $14: 50$ & Seco \\
\hline $17 / 3 / 2007$ & $16: 40$ & Seco \\
\hline $19 / 3 / 2007$ & $11: 40$ & Seco \\
\hline $20 / 3 / 2007$ & $11: 20$ & Seco \\
\hline $21 / 3 / 2007$ & $10: 30$ & Seco \\
\hline $22 / 3 / 2007$ & $16: 20$ & Seco \\
\hline $23 / 3 / 2007$ & $10: 20$ & Seco \\
\hline $26 / 3 / 2007$ & $11: 00$ & Seco \\
\hline $27 / 3 / 2007$ & $16: 30$ & Seco \\
\hline $28 / 3 / 2007$ & $11: 15$ & Seco \\
\hline $29 / 3 / 2007$ & $16: 30$ & Seco \\
\hline $30 / 3 / 2007$ & $15: 30$ & Seco \\
\hline $02 / 4 / 2007$ & $10: 55$ & Seco \\
\hline $03 / 4 / 2007$ & $15: 30$ & Seco \\
\hline $04 / 4 / 2007$ & $16: 45$ & Seco \\
\hline $05 / 4 / 2007$ & $16: 10$ & Seco \\
\hline $09 / 4 / 2007$ & $11: 20$ & Seco \\
\hline $10 / 4 / 2007$ & $09: 05$ & Seco \\
\hline $11 / 4 / 2007$ & $11: 00$ & Seco \\
\hline $12 / 4 / 2007$ & $09: 15$ & Seco \\
\hline $13 / 4 / 2007$ & $09: 25$ & Seco \\
\hline & $10: 15$ & \\
\hline & & \\
\hline & & \\
\hline
\end{tabular}




\section{DISCUSSÃO DOS RESULTADOS}

Os cálculos sobre o tempo de infiltração do sistema nos solos cujos coeficientes de permeabilidade são da ordem de $21 \mathrm{~L} / \mathrm{m}^{2}$.dia, demonstram que a infiltração ocorreria num tempo de 12 dias. Portanto, este sistema, da maneira como está projetado, com duas tubulações com 1,20 m de diâmetro, preenchidas no fundo com brita, se implantado em solo com baixa permeabilidade, pode não ser suficiente para evitar enchentes, pois para isso é necessário que haja a infiltração da água reservada no SRI em aproximadamente 24 horas, assim o sistema estaria vazio e preparado para a próxima chuva. Como então acelerar este processo de infiltração? Como no exemplo da divisão sucessiva de um cubo em pequenos cubos, o volume total permanecerá o mesmo, porém a área total, que é a somatória das áreas dos pequenos cubos resultantes cresce sucessivamente, podemos então dividir o nosso sistema em vários pequenos sistemas, aumentando sua área de contato com o solo e acelerando o processo de infiltração. Uma alternativa é o sistema ser constituído por nove tubulações drenantes com $100 \mathrm{~mm}$ de diâmetro, dispostas numa vala de $30 \mathrm{~m}$ paralela à rua; este sistema pode reter e infiltrar $2,1 \mathrm{~m}^{3}$ num tempo aproximado de 24 horas. A área de contato entre o SRI e o solo, neste caso, corresponde a $84,9 \mathrm{~m}^{2}$, quase dez vezes superior à do sistema anterior. Este valor permitirá a rápida infiltração das águas pluviais, proporcionando a infiltração de 20 $\mathrm{mm} /$ dia de chuvas até o dia subseqüente a sua ocorrência. (Tabela 7).O tempo de infiltração:

Sendo:

$$
\mathrm{T}=\mathrm{V}_{\text {total }} /\left(\mathrm{k} / 1000 \times \mathrm{A}_{\text {total }}\right)
$$

$\mathrm{T}=$ tempo de infiltração em dias;

$\mathrm{V}_{\text {total }}=$ volume total que pode ser armazenado no sistema em $\mathrm{m}^{3}$;

$\mathrm{K}=$ coeficiente de infiltração ou de permeabilidade em $\mathrm{L} / \mathrm{m}^{2}$.dia;

$\mathrm{A}_{\text {total }}=$ área total do sistema em contato com o solo em $\mathrm{m}^{2}$.

Tabela 7: Tempo de infiltração

\begin{tabular}{c|c|c|c|c|c|c|c}
\hline SRI & $\begin{array}{c}\text { Diâmetro } \\
(\mathrm{m})\end{array}$ & $\begin{array}{c}\text { Extensão } \\
(\mathrm{m})\end{array}$ & $\begin{array}{c}\mathrm{N}^{\mathrm{o}} \text { de } \\
\text { linhas }\end{array}$ & $\begin{array}{c}\text { Área total } \\
\left(\mathrm{m}^{2}\right)\end{array}$ & $\begin{array}{c}\mathrm{K} \\
\left(\mathrm{L} / \mathrm{m}^{2} . \text { dia }\right)\end{array}$ & $\begin{array}{c}\text { Volume } \\
\text { total }\left(\mathrm{m}^{3}\right)\end{array}$ & $\mathrm{T}($ dias $)$ \\
\hline 1 & 1,20 & 2 & 1 & 8,670 & 21 & 2,26 & 12,4 \\
\hline 2 & 0,10 & 30 & 9 & 84,89 & 21 & 2,12 & 1,2 \\
\hline
\end{tabular}

\section{CONCLUSÕES}

A implantação deste tipo de sistema em locais estratégicos da cidade poderá proporcionar a recarga do sistema freático, sob o ponto de vista pontual, compensando a impermeabilização causada pelo pavimento. Uma das respostas seria proporcionar o restabelecimento da descarga de base dos rios nas épocas de estiagem, bem como reduzir os alagamentos, os processos erosivos que entre outras consequiências ocasionam os assoreamentos a jusante, tão freqüentes nas bacias hidrográficas urbanizadas. 


\section{REFERÊNCIAS}

BIGARELLA, J.J.; SALAMUNI, R. Caracteres texturais dos sedimentos da Bacia de Curitiba.

Boletim da UFPR - Geologia nº 7, p. 1-159; 1962.

GIUSTI. D.A. A capital ecológica está com o lençol freático contaminado. JORNAL DO ESTADO, Curitiba, 12/07/1989.

LOPES, J.A.U. Nota explicativa da folha geológica de Curitiba. Boletim UFPR, Geologia. Curitiba, n.20; 1966.

NBR 7181/84 Ensaio de granulometria por peneiramento e sedimentação. ABNT - Associação Brasileira de Normas Técnicas.
NBR 7229/93 Projeto, construção e operação de sistemas de tanques sépticos. ABNT - Associação Brasileira de Normas Técnicas.

RIFFEL, S.B. Curva hipsométrica no mapeamento de paleosuperfícies: abordagem quantitativa. Curitiba, Universidade Federal do Paraná, dissertação de mestrado, 76p; 2005.

SALAMUNI, E.; EBERT, H.D.; HASUI, Y. Morfotectônica da Bacia Sedimentar de Curitiba. Revista Brasileira de Geociências, Volume 34, p.469-478;2004. 